\title{
Evaluation of bacteriological quality of aircraft food at the Jomo Kenyatta International Airport, Nairobi, Kenya
}

\author{
Maina T. S. N. ${ }^{1}$, Kamau L. ${ }^{2}$, Kabiru E. W. ${ }^{3}$, Ogata B. R. ${ }^{4}$, Shitandi A. ${ }^{4, *}$ \\ ${ }^{1}$ P.O. Box 803-40200 Kisii \\ ${ }^{2}$ Department of zoological sciences, Kenyatta University, P. O. Box 43844, Nairobi \\ ${ }^{3}$ Kenyatta University P.O. Box 43844, Nairobi \\ ${ }^{4}$ Division of Research and Extension, Kisii University College, P.O. Box 408-40200, Kisii Kenya
}

\author{
Email address: \\ snyairoh@gmail.com (Maina T. S. N.), lmuthoni25@yahoo.com (Kamau L.), kabiru-ephantus@ku.ac.ke (Kabiru E. W.), re- \\ search@kisiiuniversity.ac.ke (Ogata B. R.), research@kisiiuniversity.ac.ke (Shitandi. A)
}

To cite this article:

Maina T. S. N., Kamau L., Kabiru E. W. , Ogata B. R., Shitandi A. . Evaluation of Bacteriological Quality of Aircraft Food at The Jomo Kenyatta International Airport, Nairobi, Kenya. Science Research. Vol. 1, No. 1, 2013, pp. 1-8. doi: 10.11648/j.sr.20130101.11

\begin{abstract}
The production of aircraft meals can pose risks of global dimensions. In order to lay a foundation for assessing these high-risk foods, this descriptive cross sectional study sought to evaluate the microbiological quality of meals served on aircraft at the Jomo Kenyatta International Airport (JKIA), Nairobi in Kenya. Three hundred and sixty one meals were sampled under four categories of (i) Starter dishes such as hors deuver that require a fair amount of handling during preparation and which are served without reheating, (ii) Main courses, that are served hot, (iii) cold desserts; and (iv) Snack meals which include sandwiches. Isolation of microorganisms was carried out in the laboratory, enumerated and data analyzed. The antibiotic sensitivity profile of the microorganisms was also evaluated against twelve (12) antibiotics .In addition, a questionnaire was administered to assess demographic characteristics, assess food safety knowledge, practices and attitude. Statistical significance was set at $\mathrm{p}<0.05$. The results revealed contamination of aircraft food at $85 \%$ from all food sampled. Cold meals were more contaminated (68.7\%) than hot meals (16.3\%). The only pathogenic microorganism isolated was Staphylococcus aureus that accounted for $1.2 \%$ of the foods sampled. The bacteria isolated were most sensitive to Kanamycin and Aztreonam both at $81.8 \%$, while they were resistant to Ampicilin and Ampicilin at $81.2 \%$ and $84.1 \%$ respectively. In conclusion, hygiene officers, food handlers and airport health officers at the JKIA should improve and strengthen hygienic production of aircraft meals to avoid bacterial food contamination.
\end{abstract}

Keywords: Microbiological, Hygiene, Hazards, Aircraft Meals

\section{Introduction}

Microbiological hazards are the most prominent risk factors associated with airline food production [1]. Furthermore, due to limited foodborne disease investigations and surveillance in most countries including Kenya, most outbreaks go undetected [2, 3]. Jomo Kenyatta International Airport (JKIA) is an international airport serving over 20 international airlines that source their food from one point. JKIA is therefore a good representative sample for conducting such a study.

Foodborne diseases indicate that the majority of outbreaks result from faulty food handling practices [4]. In an era of frequent travel, safe food handling practices is imperative given the potential for widespread outbreaks of foodborne illnesses [5]. Lack of personal hygiene amongst food handlers is one of the most commonly reported practices con- tributing to foodborne illness while poor hand and surface hygiene is also a significant contributory factor [6]. The diseases occur as outbreak emergencies which often present a management dilemma because of the limited medical resources available on board [7]. Very little data is available particularly in Kenya regarding the occurrence of pathogenic bacteria on food served in aircrafts. It is important to identify the hazards associated with aircraft meals and to develop efficient control methods. Outbreaks resulting from exposures during air travel are particularly difficult to separate from illnesses attributable to preflight exposure [8]. Moreover, in most instances the incubation period after an in-flight exposure exceeds the flight time, so that illness occurs after passengers have dispersed. If their destinations are in different public health jurisdictions, identification of an epidemiological link between cases is especially challenging [9].

This study, investigated the microbiological quality of 
aircraft bound meals and the possible points of contamination along the production chain. The data gives insight on the possible contamination areas that could be investigated in case of food poisoning.

\section{Materials and Methods}

The study was a descriptive cross sectional study which focused on analyzing aircraft meals and describes the microorganisms found in the foods. Samples were taken at various points along the production line. It also involved administration of a questionnaire to assess food safety knowledge, attitude and practices.

The study was conducted at the Jomo Kenyatta International Airport (JKIA) food unit. JKIA serves a population of 5 million passengers yearly. Its Latitude is $1^{\circ} 19^{\prime} 48^{\prime \prime} \mathrm{S}$ and Longitude $36^{\circ} 55^{\prime} 30^{\prime}$ ' E. The Jomo Kenyatta International Airport in Nairobi is a major terminus for Kenya Airways, and other international airlines. The unit provides catering services to all commercial airlines coming to Nairobi including cargo flights and chartered flights.

A total of 361 meals were collected along the production process. Convenient and purposive sampling techniques were used and meals were divided into 4 categories namely (i) Starter dishes such as hors deuver, canapés, prawn cocktail-dishes that require a fair amount of handling during preparation and which are served without reheating; (ii) Main courses mainly meals to be served hot; (iii) Cold desserts; and (iv) Snack meals which include sandwiches, vol-au-vents, and tartlets.

Food were sampled $(\mathrm{n}=361)$ and a pathogen detection rate of 50\% from food samples and 5\% significance level was assumed $[10,11]$. Diluted samples of each category of food samples were inoculated onto nutrient agar, mannitol salt agar, (Merck, Darmstadt, Germany) and 6.5\% NaCl Mueller Hinton agar (Merck, Darmstadt, Germany) and were incubated at $37^{\circ} \mathrm{C}$ in a $\mathrm{CO}_{2}$ enriched environment for isolation and identification of Gram-positive microorganisms [12]. In brief, MacConkey agar and Eosin methylene blue agar (Merck, Darmstadt, Germany) were inoculated for the isolation of Gram-negative microorganism, incubated aerobically at $37^{\circ} \mathrm{C}$ for 18 to $24 \mathrm{~h}$. For the detection of Salmonella, Selenite $\mathrm{F}$ broth medium was used for pre-enrichment and in a non-selective liquid medium buffered peptone water and for detection, the preenricnment culture was then typically subcultured into Muller-Kauffmann Tetrathionate-Novobiocin (MKTTn) broth, and incubated for a further 24 hours at $37^{\circ} \mathrm{C}$ (MKTTn).

Identification of bacteria was carried out using standard microbiological/biochemical methods [12]. For Gram-negative bacteria, the identification battery included Gram staining, oxidase, citrate, urea hydrolysis, sulphide indole motility and Triple sugar iron test (TSI); briefly TSI agar was prepared in test tubes as a slant with phenol red and $1 \%$ lactose, $1 \%$ sucrose $0.1 \%$ glucose, sodium thiosulphate and ferrous sulphate were all added and incubated at $37^{\circ} \mathrm{C}$ for $24 \mathrm{~h}$ after which it was observed for change in colour with acid/gas production. For identification of Gram-positive bacteria, the following tests were carried out: Gram staining, catalase, tube coagulase, DNase and characteristic pigment production.

The API $20 \mathrm{E}$, a commercial test system was further used for the identification of Enterobacteriaceae and other Gram-negative rods. The test uses 23 miniaturized biochemical tests. The strip consists of 20 micro tubes containing dehydrated substrates, which is inoculated with a bacterial suspension in reference to McFarland 0.5 standard and incubated at $37 \mathrm{o} \mathrm{C}$ for between 18 to 24 hours. During incubation bacterial metabolism produces color changes that are either spontaneous or shown by addition of specific reagents.

Kirby-Bauer agar disk diffusion technique was used in testing the microbial antibiotic susceptibility [12]. The E. coli ATCC 26922 was used for quality control of growth and disc potency. The zone sizes were then interpreted by referring to the National Committee for Clinical Laboratory Standards breakpoints, and the microorganism reported to be susceptible, intermediate, or resistant [13]. The antibiotics used were representative of different antibiotic classes namely: Chloramphenicol C-30 $\mu \mathrm{g}$, Ampicillin AMP - 25 $\mu \mathrm{g}$, Tetracycline TE-25 $\mu \mathrm{g}$, Gentamicin CN $-10 \mu \mathrm{g}$, Sulfamethoxazole/ Trimethoprim SXT - $25 \mu \mathrm{g}$, Ampicilin (Amoxicillic/Clavulanic Acid) Amp - $30 \mu \mathrm{g}$, Kanamycin $\mathrm{K}-25 \mu \mathrm{g}$, Cefuroxime CXM-30 $\mu \mathrm{g}$, Aztreonam AZT-30 $\mu \mathrm{g}$, Ceftazidime CEFT-30 $\mu$ g, Cefixime CEFI -30 $\mu \mathrm{g}$, and Cefotaxime CEFO-30 $\mu \mathrm{g}$.

A self administrable questionnaire was developed for this study. The reliability of the questionnaire was also determined through a pre-test on 50 staff of the catering unit and the reliability coefficient of knowledge test was 0.74 . As a result of this reliability analysis, several test questions were modified to improve clarity. In addition, six questions were related to the demographic characteristics of 197 respondents (department, category of staff, gender, age, and number of years worked). The questionnaire was administered to all the 197 food handlers. The questions were designed and structured in four groups: (1) Food safety knowledge (2) food safety practices (3) attitude; and (4) comprehension of HACCP system and prerequisite programs within the food chain. Respondents completing the questionnaire remained anonymous. Each questionnaire took approximately 10 minutes to complete.

Quality control was carried out to ensure reliability and reproducibility of results. This included the following; strain testing, selection skill and control of inoculum's density in broth and control of culture during storage period and use of aseptic measures while inoculating at any stage and pre-testing of the data collection tools including machine verification and validation. Replicate tests were also carried out.

Data on the microbiological quality of foods was summarized using descriptive statistics such as frequencies and percentages and presented in graphs and tabular form. To examine the relationship among and between the variables, 
cross tabulations and the $\chi 2$ test, Pearson correlation coefficient were used. The questionnaire was structured to contain demographic characteristics and assess food safety knowledge, practices and attitude. Statistical significance was set at $\mathrm{p}<0.05$ using Statistical Package for Social Sciences (SPSS) version 11.5.Ethical consent was obtained from the food production units personnel department. Further consent was sought from Kenyatta University

\section{Results}

A total of 361 food samples were collected throughout the facility. Klebsiella ozaenae was the most prevalent isolate 86 (25.3\%). Three hundred and forty microorganisms were isolated (Table 1) with a number of isolates that could be pathogenic identified namely, Staphylococcus aureus, Shigella flexineri and Escherichia coli.

Table 1. Bacterial species isolated from food samples.

\begin{tabular}{lll}
\hline Bacteria isolated & \multicolumn{2}{l}{ Frequency Percentage } \\
\hline Aeromonas caviae & 5 & 1.5 \\
Citrobacter freundii & 4 & 1.2 \\
Enterobacter agglomarans & 55 & 16.2 \\
Enterobacter cloacae & 4 & 1.2 \\
Enterobacter sakazakii & 4 & 1.2 \\
Escherichia coli & 34 & 10.0 \\
Hafnia alvei & 17 & 5.0 \\
Klebsiella oxytoca & 4 & 1.2 \\
Klebsiella ozaenae & 86 & 25.3 \\
Klebsiella rhinocleromatis & 54 & 15.9 \\
Providencia alcalifaciens & 14 & 4.1 \\
Pseudomonas aeroginosa & 13 & 3.8 \\
Staphylococcus aureus & 4 & 1.2 \\
Serratia liquefaciens & 25 & 7.4 \\
Shigella flexineri & 12 & 3.5 \\
Yersinia enterocolitica & 5 & 1.3 \\
Total & 340 & 100 \\
\hline
\end{tabular}

Three categories of microorganisms were isolated from the 361 food samples namely; Bacteriological counts usually expressed as the total viable count (TVC) and used as a microbiological indicator of food quality $(60.3 \%)$, Indicator microorganisms which are present in very large numbers in environments inhabited by pathogens $(21.5 \%)$, and suspect pathogenic microorganisms $(18.2 \%)$ that should never be present in hygienically handled and effectively processed high-risk food.

The samples were analyzed from source point (Fig. 1). Raw samples were the most contaminated in terms of microbial load (Pathogenic, Indicator and Total counts) at $(42.4 \%)$ followed by samples processed at the supplier $(31.2 \%)$ then the ones sampled as airline (19.4\%) and lastly bulk at $7.0 \%$.

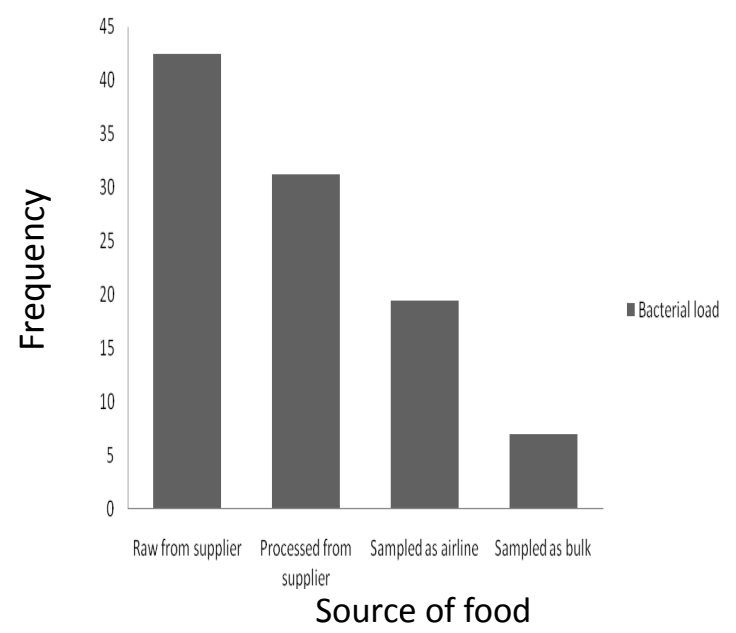

Figure 1. Frequency of microorganism (Total microbial load) from source.

Hot meals were less contaminated 59 (16.3\%) compared to cold meals $248(68.7 \%)$ thus underscoring the importance of processes such as cooking. The frequency of E. coli featured more in cold (13\%) isolates than in hot meals $(4 \%)$ isolates. Bacterial strains that are capable of causing foodborne diseases (Staphylococcus aureus, Shigella flexineri) were isolated in cold meals $(16 \%)$ and none in hot meals. E. coli which could be pathogenic was isolated in both classes of meals.

Table 2, shows the prevalence of isolates from hot meals. Isolates of Escherichia coli were isolated in food samples such as in beef $13(37.1 \%)$, chicken $4(67 \%)$ and in blanched vegetables $4(23.5 \%)$. Pork which was processed in a different room was least contaminated as compared to other hot meals $(1.7 \%)$.

Table 2. Prevalence of bacterial isolates from hot meals

\begin{tabular}{|c|c|c|c|}
\hline Food (n) & Isolate & Frequency of isolated bacteria & $\begin{array}{l}\text { Cumulative Percentage of } \\
\text { bacterial contamination }\end{array}$ \\
\hline $\operatorname{Beef}(26)$ & $\begin{array}{l}\text { Enterobacter } \\
\text { Enterobacter sakazakii } \\
\text { E. coli } \\
\text { Klebsiella ozaenae } \\
\text { Klebsiella } \\
\text { Pseudomonas } \\
\text { Serratia liquefaciens }\end{array}$ & $\begin{array}{l}11 \\
2 \\
13 \\
2 \\
3 \\
2 \\
2\end{array}$ & 59.3 \\
\hline
\end{tabular}




\begin{tabular}{llll}
\hline \multirow{2}{*}{ Chicken (26) } & E. coli & 4 & \\
& Klebsiella & 1 & 10.2 \\
Pork(14) & Pseudomonas & 1 & 1.7 \\
& Klebsiella & 1 & \\
& Enterobacter & 4 & \\
Vegetables (26) & E. coli & 4 & 28.8 \\
& Klebsiella ozaenae & 5 & 28.7 \\
& Providencia alcalifaciens & 3 & 1 \\
\hline
\end{tabular}

The results of bacterial contamination in hot meals are as shown in Fig. 2. Cooked beef products were the most contaminated category of hot meal $(59.3 \%)$ of the hot meals. These included fried beef, beef shwarma, beef curry and roasted meat. Vegetables accounted for $28.8 \%$, chicken $10.2 \%$ and lastly pork products at $1.7 \%$.

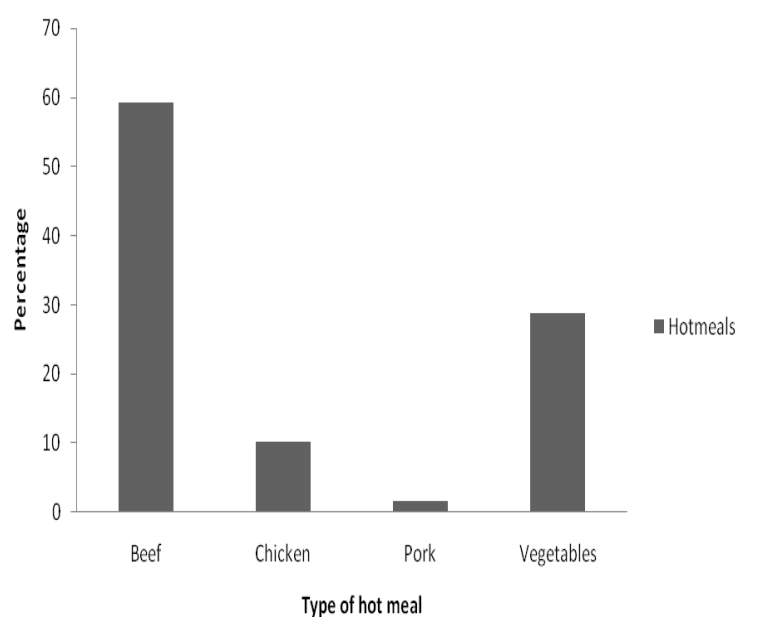

Figure 2. Proportion of contaminated hot meals.

A total of $248(68.7 \%)$ cold meals were contaminated (Table 3), with starters being the most contaminated category of cold meal which had a $62.7 \%$ of isolated bacteria. In starters the largest contamination came from Klebsiella spp, 37 isolates $(25 \%)$. Some of the pathogenic isolates were $E$. coli 13 isolates (9\%), Pseudomonas $5(3.4 \%)$ Shigella flexineria 12 isolates (8.1) and Yersinia enterolitica 5 isolates (3.4\%). For desserts Klebsiella spp 37 (51.3\%) was isolated and had the highest frequency. In snacks Klebsiella spp had the most prevalence, 12 isolates $(43.9 \%)$. Four pathogenic strains of Staphylococcus aureus (14.3\%) were isolated from snacks (chicken sandwich) which are a supplier product. In addition the Klebsiella species was isolated more accounting for $47 \%$ of all isolates from the cold meals.

Starters were found to be the most contaminated amongst the cold meals that were sampled accounting for $62.7 \%$. This was followed by desserts $(26.9 \%)$ and lastly the snack meals $(10.4 \%)$. In addition, raw materials from vegetable suppliers were more contaminated than from other suppliers $(\mathrm{p}<0.05)$.

There was a significant relationship in the type of microorganism isolated and the type of cold meal type $(\mathrm{p}<0.05)$. The microorganisms isolated from cold meals were more likely to have originated from starters than from the rest of the cold meals.).

Though not significant beef classified as hot meal had a larger percentage of contamination than other hot meals. Klebsiella spp was the most isolated microorganism accounting for $80 \%$ of all microorganisms isolated.

The diameter of zones of inhibition were measured and recorded in millimetres to determine antimicrobial susceptibility. Susceptibility results were interpreted as described by the National Committee for Clinical Laboratory Standards [13]. Kanamycin had the least resistance on the isolate (1.1\%) that was E. aggloromerans isolated from an orange goblet. Gentamicin had the second lowest resistance at 3.4\%. There was a significant $(\mathrm{p}<0.05)$ relationship in these two where the microorganisms that were resistant to Kanamycin were more likely to be resistant towards Gentamycin. Most of the isolates were resistant to Ampicilin (81.8\%) and Ampicilin (84.1\%). In addition isolates that were resistant to Ampiciline were likely to be resistant to Ampicilin.

This relationship was also evident between tetracycline and cefuroxime and also between tetracycline and Chloramphenicol. A significant $(\mathrm{p}<0.05)$ relationship was observed in the resistance and sensitivity between Tetracycline and Cefixime and tetracycline and Ceftriaxone. A caviae (100\%) was susceptible to all while E. aggloromerans was resistant to Ampicilin and Ampicilin. E. coli was resistant to Ampicilin but susceptible to Kanamycin.

Of the 197 employees taking part in the research, 81 $(41.1 \%)$ classified themselves as cold kitchen workers, 44 $(22.3 \%)$ hot kitchen, $30(15.2 \%)$ stores, 26 (13.2\%) bakery, $12(4 \%)$ catering and $4(2 \%)$ as cleansing. Majority of the respondents (64\%) were male. Average number of years worked was 7 years $(\mathrm{SD}=4.496)$. Of the 197 respondents, $86.8 \%$ were unionisable while $13.2 \%$ were in management. More than $70 \%$ of the respondents were below the age of 30 years. Majority of the respondent 27 (13\%) had worked for 4 years while 3 respondents had worked for 17, 22, and 28 years. These staff all worked in the cold kitchen.

The majority respondents, $(88.8 \%)$ had finished secondary education or had a college diploma. Staff who had finished form six accounted for $10.7 \%$ while only $1(0.5 \%)$ respondent had qualified at the university level. Of the respondents who answered the questionnaire, 64\% were male while $36 \%$ were female. 
Table 3. Prevalence of bacterial isolates from cold meals.

\begin{tabular}{|c|c|c|c|}
\hline Food (n) & Isolates & Frequency of isolated bacteria & $\begin{array}{l}\text { Cumulative Percentage of bacterial } \\
\text { contamination }\end{array}$ \\
\hline Starters (90) & $\begin{array}{l}\text { Citrobacter freundii } \\
\text { Enterobacter } \\
\text { Enterobacter cloacae } \\
\text { E. coli } \\
\text { Hafnia alvei } \\
\text { Klebsiella oxytoca } \\
\text { Klebsiella ozaenea } \\
\text { Klebsiella ornithinolytica } \\
\text { Providencia alcalifaciens } \\
\text { Pseudomonas } \\
\text { Serratia liquefaciens } \\
\text { Shigella flexineria } \\
\text { Yersinia enterocolitica }\end{array}$ & $\begin{array}{l} \\
30 \\
4 \\
13 \\
13 \\
4 \\
37 \\
10 \\
10 \\
5 \\
21 \\
12 \\
5\end{array}$ & 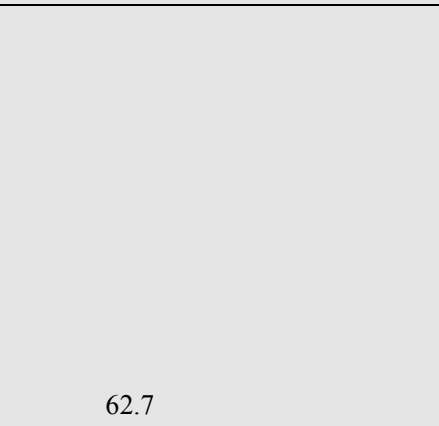 \\
\hline Dessert (90) & $\begin{array}{l}\text { Enterobacter } \\
\text { Hafnia alvei } \\
\text { Klebsiella ozaenea } \\
\text { Klebsiella ornithinolytica } \\
\text { Providencia alcalifaciens }\end{array}$ & $\begin{array}{l}4 \\
4 \\
37 \\
23 \\
4\end{array}$ & 26.9 \\
\hline Snacks (68) & $\begin{array}{l}\text { Enterobacter } \\
\text { Klebsiella ozaenea } \\
\text { Klebsiella ornithinolytica } \\
\text { Pseudomonas } \\
\text { Staphylococcus aureus }\end{array}$ & $\begin{array}{l}4 \\
4 \\
12 \\
4 \\
4\end{array}$ & 10.4 \\
\hline
\end{tabular}

To evaluate the handling practices of the food handlers and assess where personal hygiene controls were compromised, the use of tissue paper and its availability in the toilets was considered an important measure for prevention of food contamination. From table 4, there was a significant relationship between the number of years worked and action taken when there was no tissue paper in the toilet $(p<0.05)$.
Staff who had been trained recently (within a period of three months) were likely to use a thermometer more than those who had been trained more than a year before $(\mathrm{p}<$ $0.05)$. In addition college/diploma trained personnel (68\%) were likely to use canned products without blast chilling as compared to other groups. Table 4 shows different responses to questions on food handling practices.

Table 4. Food handling practices likely to contaminate food

\begin{tabular}{|c|c|c|c|c|}
\hline Statements & Never $(\%)$ & Rarely (\%) & Sometimes (\%) & Always (\%) \\
\hline Frequency of hand washing & 87.8 & 8.1 & 4.1 & 0.0 \\
\hline Frequency of practicing "clean as you go" policy & 79.7 & 16.2 & 4.1 & 0.0 \\
\hline Frequency of portioning excess food & 16.2 & 51.8 & 19.8 & 12.2 \\
\hline Frequency of washing gastonorm & 68.5 & 19.8 & 7.6 & 4.1 \\
\hline Frequency of blast chilling canned products & 23.8 & 12.2 & 23.9 & 40.1 \\
\hline Frequency of shaking hands in production & 0.0 & 40.1 & 7.6 & 52.3 \\
\hline Frequency of checking color code before serving & 95.9 & 4.1 & 0.0 & 0.0 \\
\hline Frequency of recording food temperature & 71.6 & 28.4 & 0.0 & 0.0 \\
\hline Frequency of changing gloves & 76.1 & 19.8 & 0.0 & 4.1 \\
\hline Frequency of changing apron & 20.3 & 31.0 & 20.3 & 28.4 \\
\hline
\end{tabular}

The respondents who were likely to consult with the management or totally reject non conforming products were likely to comply with food safety best practices $(\mathrm{p}<0.05)$.

\section{Discussion}

The microorganism diversity present in the various air- 
plane bound food samples was surprisingly complex and this could be linked with the fact that the majority of the food handlers (87.8\%) admitted never to wash hands upon entering production area while $76.1 \%$ also admitted to not change their gloves during their entire work shift. The hands of food handlers as well as their protective clothing should be kept clean and food handlers avoid contact with food whenever possible [14].

For many foods, especially those that are ready-to-eat, the cleanliness of food contact surfaces is likely to be identified as being critical to food safety [15]. The most frequently isolated microorganism was Klebsiella ozaenae that falls under total viable count and this is attributed to the cleanliness of the food contact surfaces.

The only pathogenic microorganism that was isolated in this study of concern was Staphylococcus aureus. Notwithstanding that low numbers are extremely unlikely to cause food poisoning with regard to pathogenicity, food contaminated with this microorganism is potentially hazardous and is evidence that the food has not been handled hygienically. Staphyloccocus aureus is the predominant species involved in staphylococcal food poisoning outbreaks, arising due to the handling of cooked foods by persons who are carried of enterotoxigenic Staphylococci in their noses or on their skin [16]. Staphylococci are ubiquitously distributed in man's environment and strains present in the nose often contaminate the back of hands, fingers and face and nasal carriers could therefore easily become skin carriers [17].

The presence of Staphylococcus aureus usually indicates a breakdown in personal hygiene or the handling of food. In this study $53.5 \%$ answered they always shook hands while in food production area. Such practices propagate spread of bacteria through cross contamination.

Hot meal samples (16.3\%) exceeded the limit of standard for $E$. coli counts of $11 \%$.. A previous study found a higher proportion of hot meals exceeding these values (15\%) for total counts and (13\%) for Escherichia coli [1]. Considerable differences in the means of total bacteria and Escherichia coli counts indicate differences in the hygienic levels between departments. However, undercooked food items such as deep-frozen blanched vegetables and steaks are commonly used in hot meals. This may be a factor contributing to the high counts of total bacteria, Escherichia coli, coliforms and Enterobacteriaceae.

For cold meals, a high total bacteria count $76.6 \%$ reflects compromised microbiological quality of cold meals, partly because appetizers, salads and desserts often include raw items such as fresh vegetables, fruits or garnishes, and they normally contain a high count of total bacteria. Many of the cold dishes $(30 \%)$ in this study had higher Escherichia coli counts than the standard permitted. The occurrence of $E$. coli, in values as $1.0 \times 10^{6} \mathrm{cfu} / \mathrm{g}$ detected, indicates contamination and poor microbiological quality. This could be as a result of inadequate sanitization of fruits and vegetables and inadequate cleaning and sanitation as $79.7 \%$ of the respondents said they did not practice the "clean as you go" policy. The source here is attributed to the raw supplies from the supplier ad failure in cleaning and sanitation proGram. Vegetables can become contaminated if they are harvested from a field with sewage contamination in it and thus the need for caterers to ensure they buy the vegetables from reputable suppliers. In addition frequent auditing of the vegetable supplier is encouraged. Flies can breed in infected feces and then contaminate food and thus the need for caterers to have an elaborate pest control proGram.

Hazard analysis critical control point (HACCP) is a food safety management system strategy which has been widely tested, and established as an effective means of preventing foodborne diseases [18]. In this study, only 3.6\% of food handlers understood the real meaning of what HACCP meant. HACCP is a preferred approach to retail food safety because it provides the most effective and efficient way to ensure that food products are safe [19]. HACCP proGrams are designed and implemented to produce the safest food possible on the basis of current scientific information and practical experience.

The prerequisite proGrams were observed not to be managed as per the required standard since $64 \%$ of the food handlers indicated that they never practice the proGram during their shift. The findings of this study indicated that $28.4 \%$ of managerial staff and $56.3 \%$ of food handlers have not received any food hygiene training. Food hygiene training should be a priority for both managers and staff as indicated by the fact that operations with individuals who have food safety certification were more likely to use appropriate food safety practices. An important finding from this study was that the concept of HACCP was not understood and that this could be impacting on the general food hygiene standards and food-handling practices of personnel.

In this study, poor food handling related to time and temperature was observed as a majority of the food handlers did not take and record food temperature. In instances where food temperature was checked, it was not recorded immediately or at all. Only $36.7 \%$ of the food handlers indicated they took end-point temperatures of all cooked food at any time during pre-preparation. The other observed food safety problem was the failure to completely thaw frozen food. Food thawing at room temperature instead of controlled areas such as cold room as required by the caterer was practiced by $75.8 \%$ of the food handlers.

Food safety training is a relevant aspect and a regulatory requirement in in-flight catering. In this study, $84.3 \%$ of the respondents had done a food hygiene course over one year past. This is a matter of public health concern, especially as human error has been suggested as a contributory factor in $97 \%$ of foodborne disease outbreaks [20]. The frequency of human error is also known to be increased by lack of training [4].

Training for caterers has been shown to improve food safety knowledge and hygiene awareness and may result in improved food safety practices [21]. However, there is considerable evidence that improved knowledge does not always translate into improved food handling behavior [22]. 
This study observed that the unit fulfilled the structural design requirements for hygiene practice, for example by providing a sensor tap hand washing sink with soap and hot water. This could suggest that basic structural requirements for the purposes of obtaining statutory licensing/approval are initially fulfilled, but on-going hygiene requirements are less carefully observed. It may also suggest that hand washing procedures, as currently practiced may not efficiently remove contaminating agents. The general role of hand washing in preventing disease is well known in the catering industry and positive attitudes to hand washing among caterers have been reported [23]. However, observational studies suggest that knowledge is not always put into practice as those who report the importance of hand washing actually don't often wash their hands before handling food [24].

There was lack of knowledge among the production staff about the critical temperatures of hot and cold ready to eat foods, acceptable refrigerator temperature ranges, periodical control of refrigerators' and freezers' thermostat settings, and etiologic agents associated with some foodborne diseases. This appeared to be related to the delay of in-service training for food service staff as $(84.3 \%)$ had their last refresher training over 1 year ago. A similar lack of knowledge about critical temperatures of hot and cold ready to eat foods, acceptable refrigerator temperature ranges and about etiologic agents, has been reported among food service staff in food service establishments [23].

From the current study, it was established that the most sensitive antibiotics were Kanamycin and Aztreonam. They both had $81.8 \%$ sensitivity on the microorganism tested. Other antibiotics showed varying resistance patterns where tetracycline had $14.8 \%$, Chloramphenicol $10.2 \%$ and Ampicillin $84 \%$.

\section{Conclusion}

In conclusion there is a need for hygiene officers, food handlers and airport health officers at the Jomo Kenyatta International airport to improve and strengthen hygienic production of aircraft meals to avoid bacterial food contamination. These results could enable authorities in the Ministry of Public Health facilitate the implementation of sanitation programmes that will be beneficial to caterers and reduce possibilities of food contamination.

\section{Acknowledgement}

The authors are grateful to the management of the JKIA food unit for allowing this study. We also thank Mr. Ian Mwaniki of CMR KEMRI and Mr. Ian Waweru of Kenya Bureau of Standards for their technical support.

\section{References}

[1] Al-Abri S, Beeching J and J Nye. Traveler's diarrhoea.
Lancet, 5: 349-360, 2005.

[2] Angelillo IF, Viggiani NM, Rizzo L and A. Bianco. Food handlers and foodborne diseases: knowledge, attitudes and reported behavior in Italy. Journal of Food Protection, 63, 381-385, 2002.

[3] Alterkruse S, Cohen L and L Swerdbin. Emerging foodborne diseases. Emerging infectious diseases, 3: 285-293,1997.

[4] Brown EA.Benson's Microbiological applications laboratory manual in general microbiology, 9th ed. McGraw-Hill Companies, Inc., New York, 230-280, 2005.

[5] Codex. Guidelines for the application of the hazard analysis critical control point. HACCP system. Rome: Codex Alimentarius Commission, FAO, 1993.

[6] Cogan TA, Slader J, Bloom F and J Humphrey. Achieving hygiene in the domestic kitchen: The effectiveness of commonly used cleaning procedures. Journal of Applied Microbiology, 92: 885-892, 2002.

[7] Daniel WW. Biostatistics: A Foundation for Analysis in the Health Sciences. $7^{\text {th }}$ edition. New York: John Wiley \& Sons, 89-99, 1999.

[8] Godil A and F Godil. Food poisoning in flight. Western J. Med., 167: 185, 1997.

[9] Gorman R, BloomWeld S and C Aley. A study of cross-contamination of foodborne pathogens in the domestic kitchen in the Republic of Ireland. International Journal of Food Microbiology, 76, 143-150, 2002.

[10] Hatakka M. Hygienic quality of foods served on aircraft. Journal of food safety.56, 33-38, 2000.

[11] Howes M, McEwen S, Griffiths M and L Harris. Food handlers' certification by home study: measuring changes in knowledge and behavior. Dairy, Food and Environmental Sanitation, 16, 737-744, 1996.

[12] Kassa H. An outbreak of Norwalk-like viral gastroenteritis in a penalized food service operation. Journal of Environmental Health,64, 9-33, 2001.

[13] Kelly ST, Harris K and R Pace. Evaluation and refinement of tmRNA structure using gene sequences from natural microbial communities.1310-1316, 2001.

[14] Lynch R, Elledge B, Griffth C and D Boatright. A comparison of food safety knowledge among restaurant managers, by training and experience, in Oklahoma County, Oklahoma. Journal of Environmental Health, 66 (2): 9-14, 2001.

[15] Martínez-Tomé M, Vera M and AM Murcia. Improving the control of food production in catering establishments with particular reference to the safety of salads. Food Control, 11, 437-445, 2000.

[16] Mc Swane D, Rue N and R Linton. Essentials of food safety and sanitation (3rd ed.). New Jersey: Pearson Education, 169- 196, 2003.

[17] Moore G and C Griffith. A comparison of surface sampling methods for Detecting coliforms on food contact surfaces. Food Microbiology, 19, 65-73, 2002.

[18] National Committee for Clinical Laboratory Standards (NCCLS). Performance standards for antimicrobial susceptibility testing, 12 th international supplement; 2004; 62-78, 2004.

[19] Olsen J. Transmission of the severe acute respiratory syndrome on aircraft. New England Journal of Medicine.349: 2416-2422, 2003.

[20] Ombui JN, Kagiko M. and M Arimi. Foodborne diseases in Kenya, East African medical journal.78(1), 2001.

[21] Portocarrero S M, Newman M and B Mikel. Staphylococcus aureus Survival, staphylococcal enterotoxin production and shelf stability of country-cured hams manufactured under different processing procedures. Meat Science, 62, 267-273, 2002. 
[22] Thompson S, de Burger R and O Kadri. The Toronto food inspection and disclosure system: a case study. British Food Journal, 107, 140-149, 2005.
[23] X2Clayton A and J Griffith. Observation of food safety practices in catering using notational analysis. British Food Journal.106 (3), 221-227, 2004 